\title{
Congenital Complete Atrioventricular Heart Block in a Pregnant Woman with Sjögren Syndrome: Prenatal Care Follow-Up and the Challenge of Intrauterine Treatment
}

\section{Bloqueio atrioventricular completo congênito em uma mulher grávida com síndrome de Sjögren: seguimento pré-natal e desafio do tratamento intrauterino}

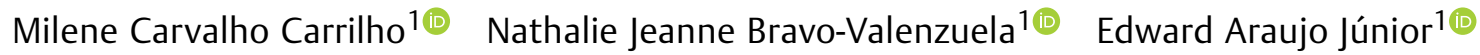 \\ ${ }^{1}$ Department of Obstetrics, Escola Paulista de Medicina, Universidade \\ Federal de São Paulo, São Paulo, SP, Brazil \\ Address for correspondence Edward Araujo Júnior, PhD, Rua \\ Botucatu 740, 04023-062, Vila Clementino, São Paulo, SP, Brazil \\ (e-mail: araujojred@terra.com.br).
}

Rev Bras Ginecol Obstet 2020;42(4):228-232.

\author{
Abstract \\ Keywords \\ - complete congenital \\ heart block \\ - maternal \\ autoantibodies \\ - prenatal diagnosis \\ - prevention \\ - intrauterine \\ treatment
}

\section{Resumo}

\section{Palavras-chave}

- bloqueio cardíaco congênito completo

- autoanticorpos maternos

- diagnóstico pré-natal

- prevenção

- tratamento intrauterino
The present report describes a case of complete atrioventricular block (CAVB) diagnosed at 25 weeks of gestation in a pregnant woman with Sjögren's syndrome and positive anti-Ro/SSA antibodies. Fluorinated steroids (dexamethasone and betamethasone) and terbuline were used to increase the fetal heart rate, but the fetal heart block was not reversible, and the administration of drugs was discontinued due to maternal collateral effects. Follow-up fetal echocardiograms were performed, and the fetus evolved with pericardial effusion, presence of fibroelastosis in the right ventricle, and ventricular dysfunction. Interruption of pregnancy by cesarean section was indicated at 34 weeks of gestation, and a cardiac pacemaker was implanted in the male newborn immediately after birth. Therapy for fetuses with CAVB is controversial mainly regarding the use or not of corticosteroids; however, monitoring of the atrioventricular interval by fetal echocardiography should be performed in fetuses from pregnant women with positive autoantibodies anti-Ro/SSA and/or anti-La/SSB to prevent the progression to CAVB.

Este relato descreve um caso de bloqueio atrioventricular completo (BAVC) diagnosticado com 25 semanas de gestação em uma mulher com síndrome de Sjögren e anticorpos anti-Ro/SSA positivos. Esteroides fluoretados (dexametasona e betametasona) e terbulina foram utilizados para aumentar a frequência cardíaca fetal, mas o bloqueio cardíaco fetal não foi reversível, e a administração dos medicamentos foi interrompida devido a efeitos colaterais maternos. Ecocardiogramas fetais de acompanhamento foram realizados, e o feto evoluiu com derrame pericárdico, presença de fibroelastose no ventrículo direito, e disfunção ventricular. A interrupção da gravidez por cesariana foi indicada com 34 semanas, e um marca-passo cardíaco foi implantado no recém-nascido do sexo masculino imediatamente após o nascimento. A terapia para fetos com BAVC é controversa, principalmente no que diz respeito ao uso ou não de corticosteroides; no entanto, o monitoramento do intervalo atrioventricular pela ecocardiografia fetal deve ser feito em fetos de mulheres grávidas com autoanticorpos positivos anti-Ro/SSA e/ou anti-La/SSB para impedir a progressão para o BAVC. received

November 7, 2019

accepted

March 9, 2020
DOI https://doi.org/

10.1055/s-0040-1709738. ISSN 0100-7203.
Copyright $\odot 2020$ by Thieme Revinter

Publicações Ltda, Rio de Janeiro, Brazil
License terms

(c) (1) 


\section{Introduction}

The incidence of atrioventricular block (AVB) is of 1 per $15,000-20,000$ live births, and $50 \%$ to $55 \%$ of these cases are caused by the presence of structural congenital heart disease. ${ }^{1}$ In total, $40 \%$ of AVBs are mainly related to SSA/Ro- or SSB/La-positive maternal antibodies. These antibodies may cross the placental circulation and lead to immune-mediated inflammation or fibrosis of fetal conduction cardiac tissue. ${ }^{2,3}$

There are three types of AVB: first, second (incomplete), and third degrees (complete). In first-degree AVB, all electrical impulses are conducted from the atria to the ventricles, with a prolonged atrioventricular (AV) conduction time. In seconddegree AVB, not all impulses are conducted from the atria to the ventricles. In complete or third-degree AVB, there is no conduction of electrical impulses from the atria to the ventricles.
Thus, complete AVB (CAVB) is characterized by AV dissociation and low ventricular heart rate $(\mathrm{HR}<60 \mathrm{bpm})\left(-\right.$ Fig. 1). ${ }^{2,3}$

In fetuses, the time between atrial and ventricular contractions ( $\mathrm{AV}$ interval) can be measured using either the ultrasound M-mode (D) or Doppler mode. The AV interval is equivalent to the mechanical PR interval, and it is considered to be extended when its value is above $150 \mathrm{~ms}$. However, the treatment of intrauterine AVB is controversial and involves close monitoring of signs of fetal heart failure., ${ }^{2,3}$ In the present article, we describe a case of AVB associated with maternal autoimmune disease, as well as the guidelines for follow-up and intrauterine treatment.

\section{Case Report}

A 35-year-old primigravida from the city of Sorocaba, Brazil, with Sjögren syndrome and anti-Ro/SSA-positive
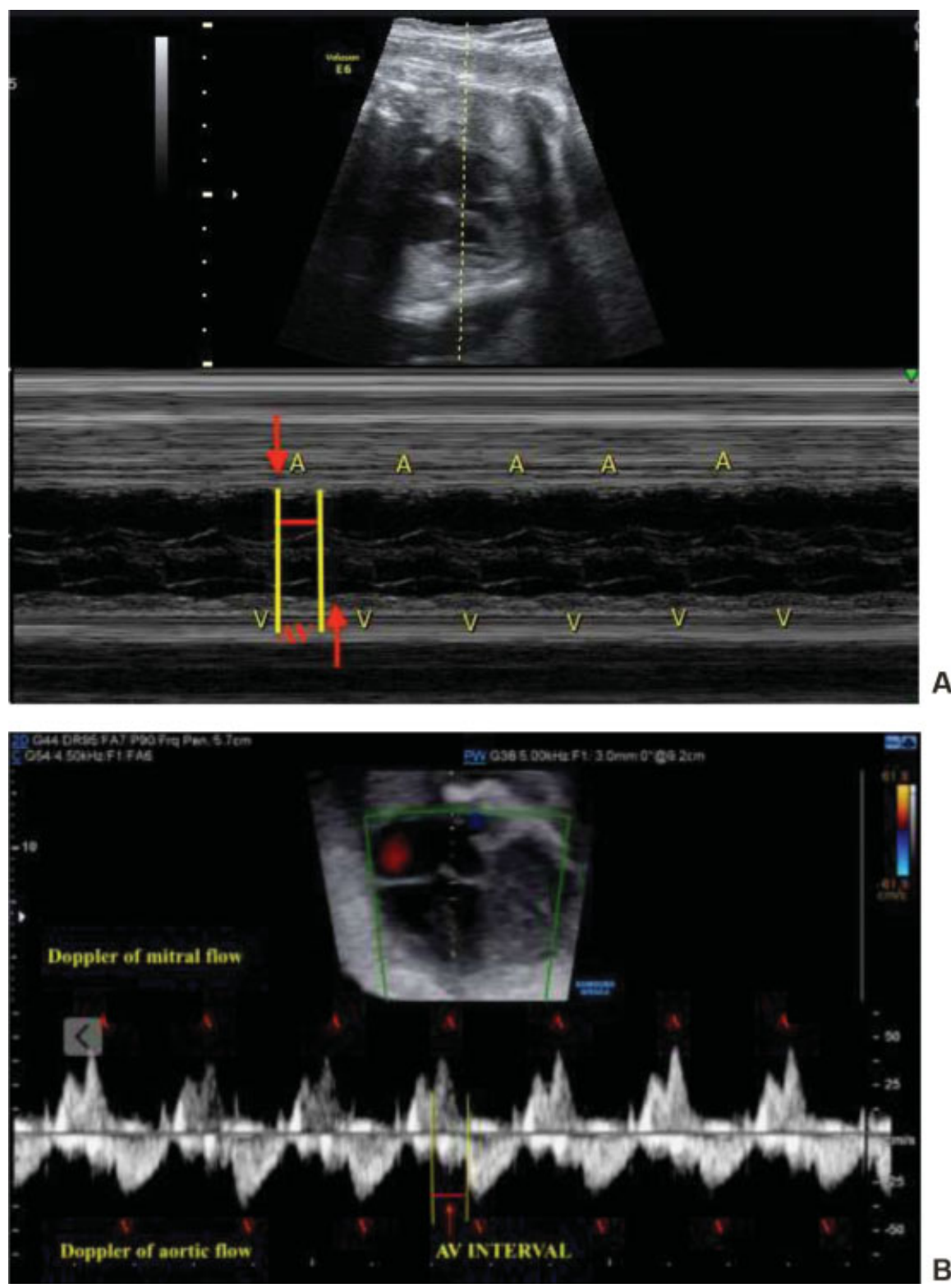

Fig. 1 Assessment of the atrioventricular interval time (AV interval, which is analogous to the electrical PR interval) by fetal echocardiogram: Mmode ultrasound (A) and Doppler of the mitral and aortic flow (B). Abbreviations: A: atrial contraction; V: ventricular contraction. 
and anti-La/SSB-negative antibodies was examined at our department with a singleton gestation of 25 weeks; the patient was referred for fetal bradycardia with a heart rate (HR) of $45 \mathrm{bpm}$ for 21 weeks. She had an initial diagnosis of left atrial isomerism associated with interventricular communication. After parental counseling, intrauterine pacemaker placement was indicated; however, the patient refused it. Clinical and echocardiographic follow-ups were conducted, and the mother was treated with corticosteroids and $\beta$-adrenergic agents.
The patient was diagnosed with gestational diabetes mellitus due to corticosteroid use ( $8 \mathrm{mg} /$ day), and had a HR of $200 \mathrm{bpm}$ associated with symptoms after terbutaline use ( $400 \mathrm{mg} /$ day). The first fetal echocardiogram, after a protocol to screen for congenital heart disease, showed an anatomically normal heart with bradycardic rhythm, ventricular $\mathrm{HR}$ of $40 \mathrm{bpm}$, and atrial $\mathrm{HR}$ of $147 \mathrm{bpm}$, and a diagnosis of CAVB was made (-Fig. 2). The administration of terbutaline was suspended and corticosteroid weaning was started due to the side effects, with improvement in
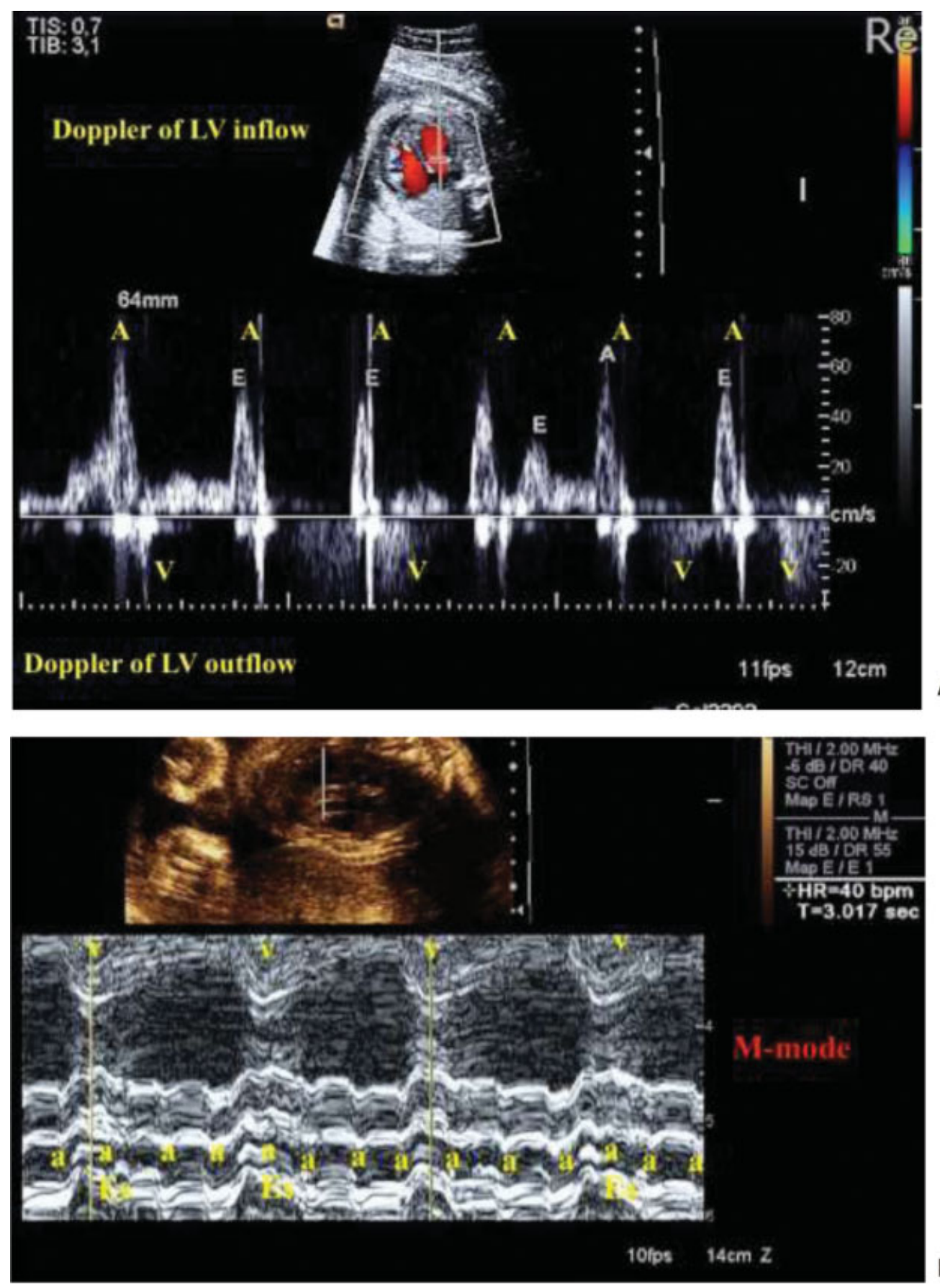

B

Fig. 2 (A) Left inflow and outflow tract view showing complete atrioventricular (AV) block by analysis of the inflow and outflow tract Doppler waves. (B) M-mode ultrasound showing complete AV block by atrial and ventricular wall movement recordings. Note presence of atrial extrasystoles. Abbreviations: A: atrial contraction; V: ventricular contraction; aEs: atrial extrasystoles; HR: heart rate. 


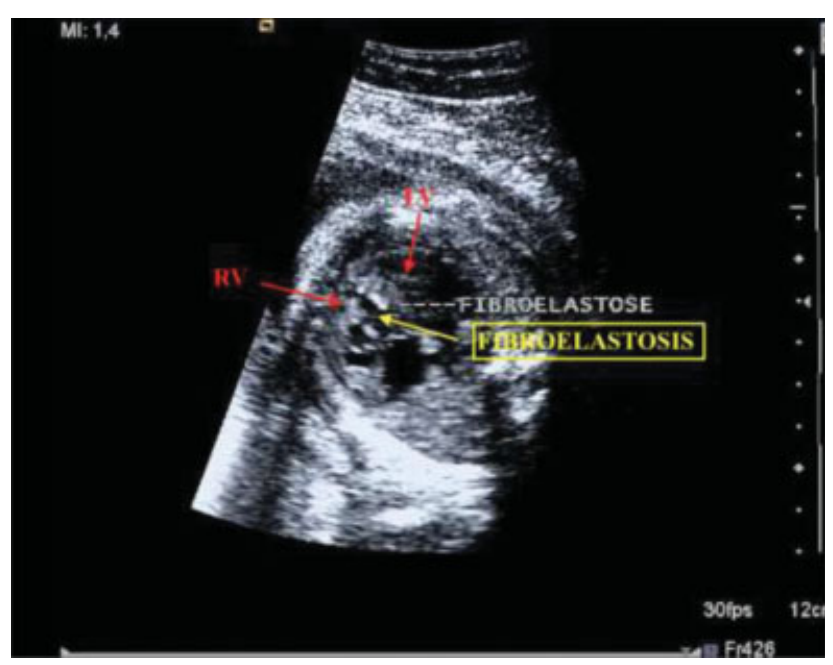

Fig. 3 Fetal echocardiogram performed at 32 weeks of gestation showing signs of RV fibroelastosis. Abbreviations: RV: right ventricle, LV: left ventricle; HR: heart rate.

fasting glucose and glycated hemoglobin (HbA1c) levels. At 32 weeks of gestation, the fetus showed effusions on echocardiographic follow-up with discrete pericardial effusion in the lateral wall of the right atrium and suspected right ventricular fibroelastosis ( - Fig. 3). Another echocardiogram at 34 weeks showed worsening of the fetal pericardial effusion and ventricular dysfunction, and an emergency delivery was indicated. A cesarean section was performed, and a male infant was delivered, weighing $2,240 \mathrm{~g}$, with Apgar scores of 4,7 , and 9 at the $1 \mathrm{st}, 5^{\text {th }}$, and 10 th minutes respectively. The newborn was intubated in the delivery room. Transthoracic echocardiography immediately after birth confirmed normal cardiac anatomy, presence of moderate pericardial effusion without signs of restriction (-Fig. 2), and an HR of $40 \mathrm{bpm}$. Epinephrine was started at a dose of $0.1 \mu \mathrm{g} / \mathrm{kg} / \mathrm{min}$ for hemodynamic support, and a 2-hour pacemaker was implanted. The infant's condition was stable, and he was successfully extubated at 5 days of age, after extubation failure due to pulmonary hypertension in the first 24 hours. The infant was discharged in 10 days with an HR of $130 \mathrm{bpm}$ and good clinical condition.

\section{Discussion}

Sjögren syndrome is one of the three most common autoimmune diseases, with a prevalence of 0.1 to $5 \%$ of the population, ${ }^{4}$ occurring most often in women, in a 9:1 ratio, with a higher prevalence in the fifth decade of life. ${ }^{2}$ This disease is related to the presence of autoantibodies in $60 \%$ of the cases. ${ }^{3}$ These antibodies cause damage to the fetal heart conduction system, leading to CAVB, which, in turn, is associated with a $30 \%$ mortality rate. ${ }^{5}$

Complete atrioventricular block is characterized by a complete dissociation between atrial and ventricular activity, with ventricular frequency usually below $60 \mathrm{bpm}$, in which fetuses with ventricular $\mathrm{HR}<55 \mathrm{bpm}$ have a poorer prognosis ${ }^{6}$ due to the presence of endocardial fibroelastosis and signs of fetal hydrops. ${ }^{7,8}$
The follow-up and treatment of these cases is not wellestablished, and the use of fluorinated corticosteroids (dexamethasone or betamethasone at a dose of 4 to $8 \mathrm{mg} /$ day) is indicated in cases of incomplete AVB (first or second degrees) to prevent progression to CAVB or to achieve incomplete AVB reversal and decrease myocardial fibroelastosis. There is evidence against the use of corticosteroids in cases of CAVB due to the deleterious effects on pregnant women and the presence of irreversible fibrosis in the cardiac conduction tissue of the fetus. ${ }^{9-11}$

In the present case, the woman had been using dexamethasone since the diagnosis of CAVB at 23 weeks, without significant change in $\mathrm{HR}$, which was maintained at $\sim$ $47 \mathrm{bpm}$. However, the patient developed gestational diabetes mellitus; thus, the administration of the medication was discontinued after a gradual dose reduction. Some studies point to the occurrence of side effects of corticosteroids and recommend that the medication be discontinued in their presence. ${ }^{2,3,9}$ Eliasson et $\mathrm{al}^{9}$ performed a multicenter study with 175 patients and demonstrated that, apart from the adverse side effects, the use of corticosteroids showed no beneficial effect in fetuses with $\mathrm{HR}<50 \mathrm{bpm}$ or on the presence of hydrops and/or cardiomyopathy.

Some authors recommend the use of intravenous immunoglobulin in cases in which the fetus has systolic cardiac dysfunction and/or signs of endocardial fibroelastosis and/or myocarditis; however, its efficacy has not been proven., ${ }^{2,3}$ Regarding the use of $\beta$-sympathomimetics, the patient used terbutaline and developed tachycardia and an estimated HR of $200 \mathrm{bpm}$, which was associated with symptoms such as malaise and tremors. Yoshida et $\mathrm{al}^{12}$ reported the case of a pregnant woman at 22 weeks of gestation with CAVB in which terbutaline was chosen as a $\beta$-sympathomimetic drug due to good transplacental passage, to increase the fetal HR and prevent myocardial failure. Another study reported a $10 \%$ to $15 \%$ increase in fetal HR. ${ }^{6}$ However, despite the increase in fetal $\mathrm{HR}$, there are no studies demonstrating a benefit in terms of survival of these fetuses with this treatment approach. ${ }^{12}$

As there are no studies demonstrating that the use of these medications can modify the survival of these fetuses, pregnancy monitoring was performed every two days after the discontinuation of the corticosteroids and terbutaline, at which time the signs of heart failure were evaluated with the Huhta cardiovascular score ${ }^{13}$ along with HR monitoring.

Percutaneous fetal implantation of a cardiac pacemaker has been shown to be effective in experimental studies, suggesting that it could be used in hydropic human fetuses with CAVB. However, there are no studies that prove its effectiveness in human fetuses. 3,14

Some authors recommend continuous fetal echocardiographic surveillance from 16 weeks of gestation in pregnant women with Sjögren syndrome or other autoimmune diseases with positive anti-Ro/SSA and/or anti-La/SSB antibodies for the early diagnosis and early treatment of first- and seconddegree AVB. ${ }^{2,3,15}$ Patients with anti-Ro/SSA and/or anti-La/SSB antibodies should be advised of the high risk of fetal AVB or neonatal systemic lupus erythematosus, so that the pregnancy can be planned during periods of disease stability, that is, when 
the patient has low levels of anti-Ro/SSAor anti-La/SSB antibodies. Since 2017, the European League Against Rheumatism (EULAR) has been recommending that hydroxychloroquine should be used during pregnancy, even when the pregnant woman is asymptomatic. ${ }^{16}$

The follow-up and treatment of fetuses with CAVB is still controversial in terms of the use of corticosteroids. However, attention should be paid to the fetuses of pregnant women with positive autoantibodies, with monitoring by fetal echocardiography, to prevent progression to CAVB.

\section{Conflict of Interests}

The authors have none conflict of interests to declare.

\section{References}

1 Bordachar P, Zachary W, Ploux S, Labrousse L, Haissaguerre M, Thambo JB, et al. Pathophysiology, clinical course, and management of congenital complete atrioventricular block. Heart Rhythm. 2013; 10(05):760-766. Doi: 10.1016/j.hrthm.2012.12.030

2 Pedra SRFF, Zielinsky P, Binotto CN, Martins CN, Fonseca ESVB, Guimarães ICB, et al. Brazilian Fetal Cardiology Guidelines - 2019. Arq Bras Cardiol. 2019;112(05):600-648. Doi: 10.5935/abc.20190075

3 Donofrio MT, Moon-Grady AJ, Hornberger LK, Copel JA, Sklansky MS, Abuhamad A, et al; American Heart Association Adults With Congenital Heart Disease Joint Committee of the Council on Cardiovascular Disease in the Young and Council on Clinical Cardiology, Council on Cardiovascular Surgery and Anesthesia, and Council on Cardiovascular and Stroke Nursing. Diagnosis and treatment of fetal cardiac disease: a scientific statement from the American Heart Association. Circulation. 2014;129(21):2183-2242. Doi: 10.1161/01.cir.0000437597.44550.5d

4 Gupta S, Gupta N. Sjögren syndrome and pregnancy: a literature review. Perm J. 2017;21:16-047. Doi: 10.7812/TPP/16-047

5 Tsuboi H, Sumida T, Noma H, Yamagishi K, Anami A, Fukushima K, et al. Maternal predictive factors for fetal congenital heart block in pregnant mothers positive for anti-SS-A antibodies. Mod Rheumatol. 2016;26(04):569-575. Doi: 10.3109/14397595.2015.1106661

6 Zemlin M, Bauer K, Dörner T, Altinöz H, Versmold H. [Intrauterine therapy and outcome in four pregnancies of one mother with anti ro-autoantibody positive Sjoegren's syndrome].Z Geburtshilfe Neonatol. 2002;206(01):22-25. Doi: 10.1055/s-2002-20947. German.

7 Aoki H, Inamura N, Kawazu Y, Nakayama M, Kayatani F. Fetal echocardiographic assessment of endocardial fibroelastosis in maternal anti-SSA antibody-associated complete heart block. Circ J. 2011;75(05):1215-1221. Doi: 10.1253/circj.cj-10-1032

8 Nield LE, Silverman ED, Taylor GP, Smallhorn JF, Mullen JBM, Silverman $\mathrm{NH}$, et al. Maternal anti-Ro and anti-La antibodyassociated endocardial fibroelastosis. Circulation. 2002;105(07): 843-848. Doi: 10.1161/hc0702.104182

9 Eliasson H, Sonesson SE, Sharland G, Granath F, Simpson J, Carvalho JS, et al; Fetal Working Group of the European Association of Pediatric Cardiology. Isolated atrioventricular block in the fetus: a retrospective, multinational, multicenter study of 175 patients. Circulation. 2011;124(18):1919-1926. Doi: 10.1161/ CIRCULATIONAHA.111.041970

10 Lopes LM, Tavares GMP, Damiano AP, Lopes MAB, Aiello VD, Schultz R, et al. Perinatal outcome of fetal atrioventricular block: one-hundred-sixteen cases from a single institution. Circulation. 2008;118(12):1268-1275. Doi: 10.1161/CIRCULATIONAHA.107. 735118

11 Pike JI, Donofrio MT, Berul CI. Ineffective therapy, underpowered studies, or merely too little, too late? Risk factors and impact of maternal corticosteroid treatment on outcome in antibody-associated fetal heart block. Circulation. 2011;124(18):1905-1907. Doi: 10.1161/CIRCULATIONAHA.111.061267

12 Yoshida H, Iwamoto M, Sakakibara H, Shigeta H, Hirahara F, Sato K. Treatment of fetal congenital complete heart block with maternal administration of beta-sympathomimetics (terbutaline): a case report. Gynecol Obstet Invest. 2001;52(02):142-144. Doi: $10.1159 / 000052960$

13 Hofstaetter C, Hansmann M, Eik-Nes SH, Huhta JC, Luther SL. A cardiovascular profile score in the surveillance of fetal hydrops. J Matern Fetal Neonatal Med. 2006;19(07):407-413. Doi: $10.1080 / 14767050600682446$

14 Gardiner HM. In utero intervention for severe congenital heart disease. Best Pract Res Clin Obstet Gynaecol. 2019;58:42-54. Doi: 10.1016/j.bpobgyn.2019.01.007

15 Rein AJJT, Mevorach D, Perles Z, Gavri S, Nadjari M, Nir A, et al. Early diagnosis and treatment of atrioventricular block in the fetus exposed to maternal anti-SSA/Ro-SSB/La antibodies: a prospective, observational, fetal kinetocardiogram-based study. Circulation. 2009;119 (14):1867-1872. Doi: 10.1161/CIRCULATIONAHA.108.773143

16 Andreoli L, Bertsias GK, Agmon-Levin N, Brown S, Cervera R, Costedoat-Chalumeau $\mathrm{N}$, et al. EULAR recommendations for women's health and the management of family planning, assisted reproduction, pregnancy and menopause in patients with systemic lupus erythematosus and/or antiphospholipid syndrome. Ann Rheum Dis. 2017;76(03):476-485. Doi: 10.1136/annrheumdis-2016-209770 